\title{
Multi-Criteria Decision Analysis and GIS Approach for Prioritization of Drinking Water Utilities Protection Based on their Vulnerability to Contamination
}

\section{A. Alvarado, M. V. Esteller, E. Quentin \& J. L. Expósito}

\section{Water Resources Management}

An International Journal - Published for the European Water Resources Association (EWRA)

\section{ISSN 0920-4741}

Volume 30

Number 4

Water Resour Manage (2016)

30:1549-1566

DOI 10.1007/s11269-016-1239-4

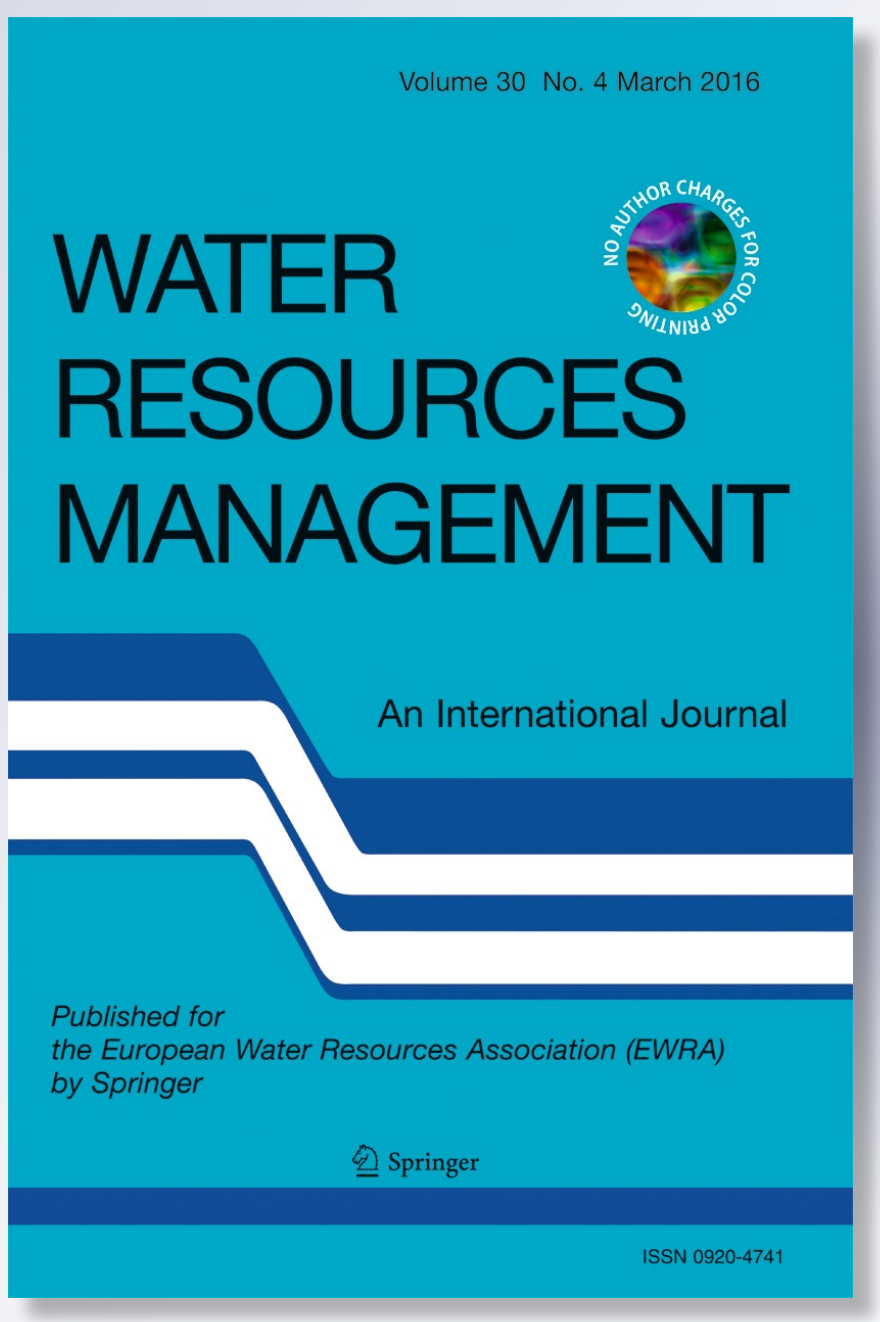

Springer 
Your article is protected by copyright and all rights are held exclusively by Springer Science +Business Media Dordrecht. This e-offprint is for personal use only and shall not be selfarchived in electronic repositories. If you wish to self-archive your article, please use the accepted manuscript version for posting on your own website. You may further deposit the accepted manuscript version in any repository, provided it is only made publicly available 12 months after official publication or later and provided acknowledgement is given to the original source of publication and a link is inserted to the published article on Springer's website. The link must be accompanied by the following text: "The final publication is available at link.springer.com". 


\title{
Multi-Criteria Decision Analysis and GIS Approach for Prioritization of Drinking Water Utilities Protection Based on their Vulnerability to Contamination
}

\author{
A. Alvarado ${ }^{1}$ - M. V. Esteller ${ }^{1}$ - E. Quentin ${ }^{1,2}$. \\ J. L. Expósito ${ }^{1}$
}

Received: 11 September 2014 / Accepted: 17 January 2016 /

Published online: 27 January 2016

(C) Springer Science+Business Media Dordrecht 2016

\begin{abstract}
This work presents the use of multi-criteria decision analysis (MCDA) as a decision tool to facilitate the process of prioritization of drinking wells that would need more protection before contamination risk. In this study, three aspects of the protection of the groundwater quality were taken into account: natural, anthropic and technical. From these aspects, elements more representative were selected, which can be quantified with available and easily accessible information. Considering those elements, selection criteria were defined which have been represented by: population distribution indicator, human development index, land use, index for aquifer vulnerability to contamination, well age and well yearly pumping rate. The developed method has been applied to drinking supply wells located in the Toluca Valley aquifer (Mexico), and implied the generation of the thematic maps of the defined selection criteria. For the MCDA, the values of each map were converted to the same scale, each criterion was weighted in function of its importance according to the objective and there were aggregated by the way of a lineal combination. The obtained result is a map that shows the level of protection priority of the supply wells. This map can offer information to the stakeholder in a relative short time and contribute to accelerate the actions aimed to protect the quality of the vital underground liquid.
\end{abstract}

Keywords MCDA · GIS · Groundwater - Well protection

M. V. Esteller

mvestellera@uaemex.mx

1 Centro Interamericano de Recursos del Agua (CIRA), Facultad de Ingeniería, Universidad Autónoma del Estado de México, Cerro Coatepec S/N C.U, 50130 Toluca, Estado de México, Mexico

2 Present address: Plataforma EpiSIG. Instituto Nacional de Investigación en Salud Pública (INSPI), Calle Iquique N14-285 y Yaguachi, Quito, Pichincha, Ecuador 


\section{Introduction}

Groundwater constitutes the supply source more sure and important of water for human necessity, specifically in urban areas of developing countries, in arid and semiarid regions or in islands. A pre-requirement for water use aimed to cover human necessities is that the quality must be desirable and stable, which is more easily fulfill with source of ground water protection (Foster et al. 2002). Prevention is the premise for the protection of groundwater in front of pollution, since it is difficult and expensive to apply remediation methods in aquifers.

According to the importance of groundwater, the protection of its quality is quite unusual. It must be that the groundwater quality is being affected by the pollution processes. This loss of quality can be harmful to its usefulness, disturb seriously its availability over all for human consumption and affect the health of the population.

In that sense, instead of applying a method for the protection of the entirety of the aquifer, it results more profitable and less limiting for economic development to define a control level at a more local scale by mean of the delimitation of simple and robust zones (De Loë et al. 2002), which can be defined on the basis of wellhead protection areas (Exposito et al. 2010), where it must be decided which anthropogenic activities are possible and where it can be located, with an acceptable risk for groundwater (Foster et al. 2002).

In aquifers where a lot of wells are located, oriented to a public-urban use and where there exists limits on economic as well as human resources, it is impossible to contemplate the protection of all the wells, that is why a previous planning is necessary to establish which wells are having priority when they have to be protected when facing a possible pollution of groundwater, which justify the necessity to fix some criteria to define this priority order.

A tool that can be used to establish this priority is the multi-criteria decision analysis or evaluation (MCDA) (Karnib 2004). The MCDA is a process that evaluates various criteria to reach a specific objective which allows taking a decision (Saaty 1980). The process consists in defining a reduced group of criteria involved in the problem to subsequently weight the criterion according to the influence that it has for the achievement of the objective of the analysis. Afterwards, by the way of the method that considers the relative weight of each criterion, the criteria are aggregated, and as a result a unique index for evaluation is created that implies the best fulfillment of the decision criteria established, and as such the best option is obtained.

According to the terminology used by Eastman (2012) criterion is the basis for taking decision that can be measured and evaluated, it can be of 2 types: factors and constraints. A factor is a criterion that enhances or reduces the ability of an alternative to the specific activity and a constraint is a criterion that limits the alternatives under consideration.

MCDA is a useful tool for the simplification of complex situations and encourages multidisciplinary work, that is why it has been frequently used in situation of decision-making in the field of water resources (Hajkowicz and Collins 2007), as it is the case in integrated water management (Korteling et al. 2013; Calizaya et al. 2010), prioritization of watersheds for the implementation of soil conservation plans (Chowdary et al. 2013), vulnerability assessment of human supply sources (Joerin et al. 2010), evaluation of multipurpose water reservoirs (Ribas 2014), prioritization in the execution of projects to meet water demand (Karnib 2004), or the selection of areas for groundwater exploitation (Kumar et al. 2014; Adiat et al. 2012; Doumouya et al. 2012).

In many of these studies, the introduction of this type of analysis was carried out using a Geographic Information System (GIS). Among the different available GIS software, it can be mentioned the Idrisi GIS from Clark Labs (Eastman 2012), which includes a module for decision support, called Multi-Criteria Evaluation (MCE), based in an Analytical Hierarchy 
Process (AHP), which can be used to facilitate the identification and classification process of the possible solutions to the studied problem, in this case the prioritization of drinking water utilities protection.

Taking into account the tools that exist nowadays to facilitate decision taking and considering the need that exists to adequately protect sources of drinking water, the aim of this research was to develop a methodology based on the application of the MCDA in a GIS environment for the identification and ranking of sources of water supply for human consumption with most need of protection from possible contamination events, taking into account not only technical aspects but also scientific and social aspects. As an example, a case study is presented in the Valley of Toluca aquifer, Mexico.

\section{Materials and Methods}

As a first step, a definition of the problem was carried out, from which one issue is the alteration of groundwater quality as a consequence of contaminants diffusion from soil to the aquifer and the principal elements considered in this question are: human activities (pollution spots), hydrogeological characteristics, characteristics of the supply sources (wells) and socioeconomic aspects.

From this issue, a 3-steps methodology was defined:

\subsection{Step 1: Identification of Factors, Indicators and Indices}

Table 1 details the considered criteria, which are related with natural, anthropogenic and technical aspects, the indicators and indices that represent those criteria, the methods used to obtain the value of each of the indicators and indices, as well as the required information to apply these methods.

The selection of the criteria, as well as the way to evaluate them through indices and indicators, was based fundamentally on the available information for the studied aquifer. If in other study cases some other data of different nature exist that can define additional criteria, there is not any limitation to integrate those criteria to this methodological development.

\section{(a) Natural aspect}

This aspect includes environmental setting characteristics that naturally make possible the groundwater quality modification. For this aspect the criterion of aquifer vulnerability to pollution was taken into account. Based on the availability of the information and on the method simplicity, the GOD index of vulnerability was considered (Foster and Hirata 1988). GOD is a rating system method that assesses vulnerability by means of three variables: groundwater occurrence $(\mathrm{G})$, overall lithology of aquifer, $(\mathrm{O})$ and depth to groundwater table (D). The final index is obtained from the formula: GOD Index $=\mathrm{G} * \mathrm{O} * \mathrm{D}$.

(b) Anthropogenic aspect

This aspect procures reflecting the pressure from the population over the groundwater and implies situations where mankind can affect its quality. The considered criteria were: i) population distribution, ii) development level of the population and iii) land use. The choice of the population distribution criteria was based in the fact that with more population density, its water consumption is greater. To assess this criterion, the Population Distribution Indicator (PDI) was considered, since it shows the population quantity dispersed over a territory.

Other criterion is the human development level. Human development is the process of 
A. Alvarado et al.

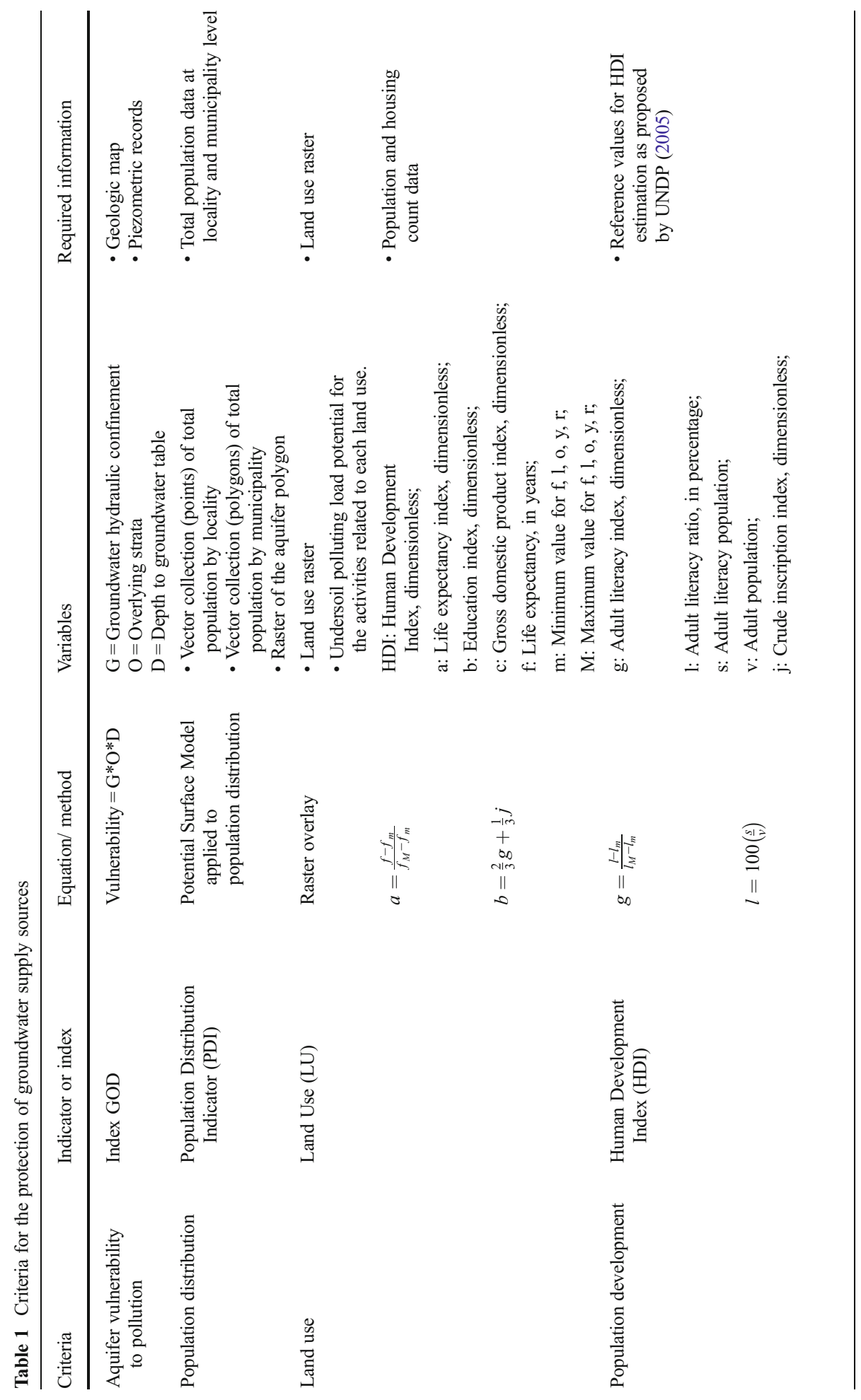




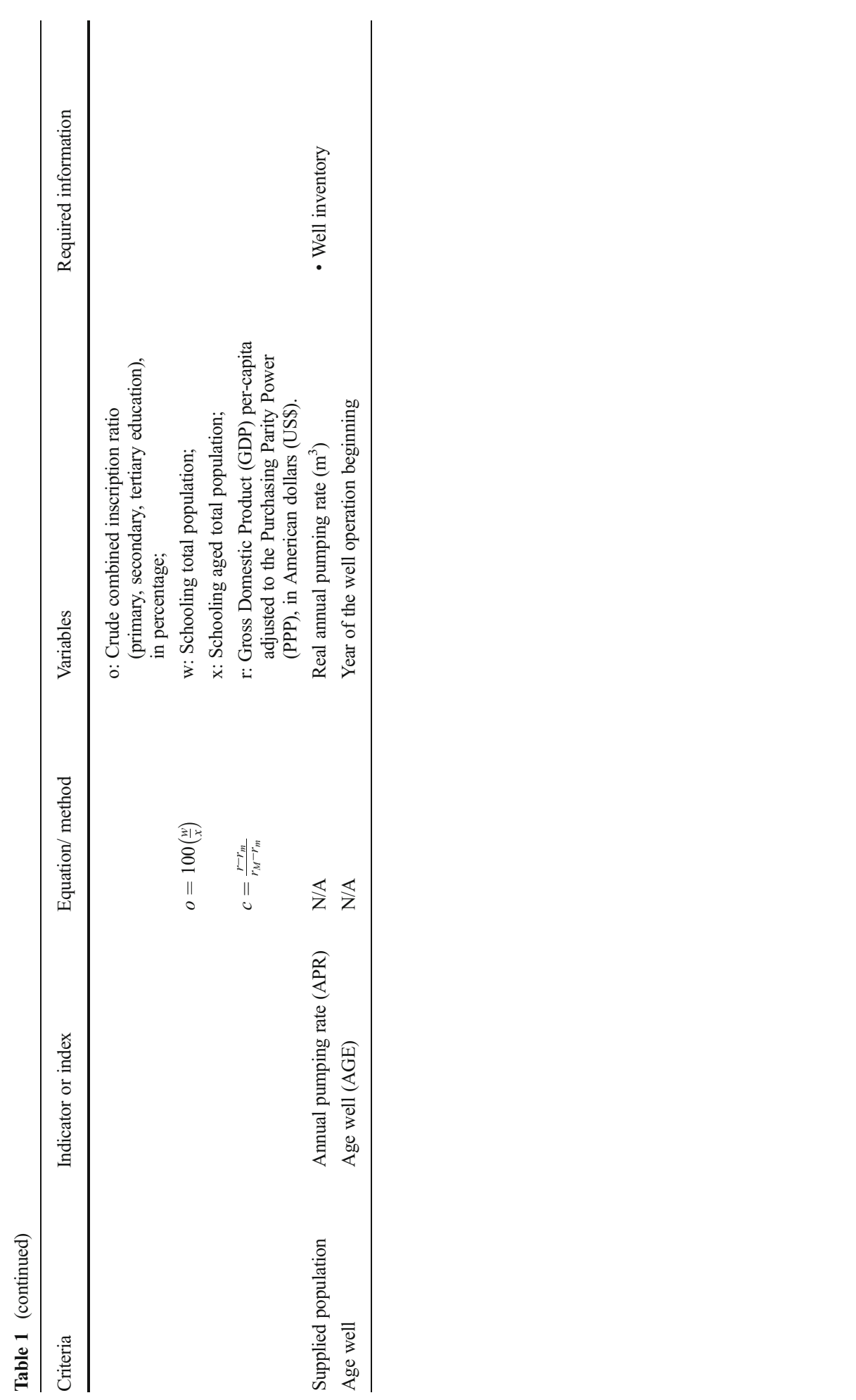


increasing choice of the individuals, which is aimed to expand the opportunities of people to live a healthy, creative life with the adequate means to get on in his social setting (UNDP 2005). It is to be noted that poverty and socioeconomic weakness are generally factors that are negatively related with the environmental management capacity, making population vulnerable and social systems facing risks, ie. social vulnerability (CESPEDES 2001). Consequently, population vulnerability before groundwater supply pollution is directly related with human development level, for which community with less development could result more negatively impacted in health and economy. To evaluate this criterion, the Human Development Index (HDI) was defined, which considers three basic dimensions: health, education and income, and whose value can range from 0 to 1 .

The last criterion is the land use, which allows to identify, classify and categorize the danger degree of potential source of groundwater pollution. The Land Use Indicator (LU) shows the different territory zones joining information about industrial parks, urban areas, agricultural fields, etc.

(c) Technical aspect

This approach evaluates the importance of water uptake that contributes to population supply and indirectly, for its susceptibility to encourage aquifer water pollution caused by the deterioration of the same uptake structure. It is evaluated with two criteria: well age and annual pumping rate.

Regarding the structure age criterion, it is necessary to consider that those constructions have an average designed useful life of 25 years (Custodio and Llamas 1996).

It must be underlined that well protection against pollution can change with the pass of time since the decline of the uptake can be seen in various phenomena such as cracks in well structure, incrustation emergence, corrosion, sand sedimentation, leakage of the pump lubrication system, etc.. The identification of the oldest wells was obtained with Age Well Indicator (AGE), in years.

The choice of the criterion of annual extraction rate was based on the fact that it is a measure that reflects the economic activity intensity, the supplied population size at which each well is furnishing, as well as the geographic distribution. To value this criterion, an indicator of Annual Pumping Rate (APR) was generated, which allow to identify the wells that supply more population according to the yearly cubic meters of water extracted.

\subsection{Step 2: Calculus of Indicators and Indices}

For the calculus of each one of the indicators and indices, the following steps were completed:

\section{(a) Geodatabase structure}

The geodatabase is a digital collection of maps and related information, which elements are cartographic data and attributes. The recommended steps to structure de geodatabase are: i) preparing a catalog of information to use, ii) searching and obtaining data, iii) designing the geodatabase structure, and iv) configuring of the geodatabase in GIS.

(b) Calculus algorithm

Each one of the indicators and indices is calculated and the corresponding map is obtained. The resulting maps are considered as criteria for assigning priorities and are entry to apply the MCDA.

To facilitate the calculus work, in addition to the native Idrisi GIS operators (Eastman 
2012), the Integrated Water Management module (Manzano 2007), was exploited. This tool facilitated the calculus of PDI and HDI. Nevertheless, it is also possible to calculate the indicators and indices in a spreadsheet and afterwards convert them to map.

In case of the PDI, it was assessed by way of an interpolation of the original values of point population (localities) with the interpolation method called gravity model to obtain a potential surface for population distribution (Eastman 2012). The potential surface is calculated by a method similar to the interpolation by distance weighted average, but use the gravity model which was developed to model potential interaction between masses measured at sample points and as such allow that for pixels far from any point, the value is kept to null which is more adapted to the population density variable. This weighting surface is then use to disaggregate the total population inside a polygonal object. The population values obtained for each cell are an approximation of population distribution when crude information is not available at this spatial resolution level. This distribution model is recommended when a clear polarity is known in the population distribution of a territory (Manzano 2007).

For the HDI calculus, the three dimensions of health, education and income were considered. The basis of the calculus is the determination of an index for each dimension (life expectation index, education index and gross domestic product index) and for this the deviation with respect to a reference value (minimum and maximum) was taken into account, which generally represents a wished measured achievement (López et al. 2004). The human development categories are: Low: $\mathrm{HDI} \leq 0.5$, Medium: $0.5>\mathrm{HDI} \leq 0.8$ and High: $\mathrm{HDI}>0.8$ (UNPD 2005).

In the raster of the LU, all uses were ranked and ordered, according to their potential for contaminating groundwater and the specific issue of the region. For this criterion, the Pollutant Origin and its Surcharge Hydraulically (POSH) classification can be taken as a reference (Foster and Hirata 1988). The pollution sources considered were: cropland, industrial and urban land uses.

\subsection{Step 3: Geomatics Multi-Criteria Decision Analysis}

The MCDA supported by the Idrisi GIS includes the following steps (Eastman 2012):

(a) Objectives definition

The number of proposed objectives should be minimal and these goals must be oriented to the solution of decision problem, which consists in determining the priority of supply wells protection.

(b) Criteria definition

The indicators and indices were used as factors and the raster polygon of the aquifer limit was considered as the only constraint, forming a mask of the study zone.

(c) Fuzzy scaling of factors

The raster of the factors, by their nature, are on different scales. Consequently, it is necessary to transform all of them on a byte scale from 0 to 255 . This rescaling is aimed to facilitate comparison and operations between various criteria. However, it can be the case that one factor should not be rescaled if it is already adjusted to the mentioned scale, by means of reassigning values (with the Assing module), executed outside of the Decision Wizard module, previous to the introduction of the factor raster. Applying this process is necessary for raster with few categories not ordinal as can be the land use. In the Decision Wizard module, it must 
be specified when entering each factor if a fuzzy operation must be applied and the name of the corresponding result.

If it appears clearly that the factors are using a continuous scale with min and max different from 0 and 255 respectively, the Fuzzy module has to be called by the Decision Wizard module in order to rescale factors using fuzzy membership functions and it is convenient for computing reasons to convert to a byte scale. The highest value on the new scale represents the best suitability for the objective under analysis.

To rescale each one of the factor images require, firstly, to know the minimum and maximum values of the original scale, which are read from the metadata of the input raster. It is also necessary to select the membership function and the thresholds of adjustment for each factor, this operation being based on the fuzzy logic theory. Fuzzy sets (Zadeh 1965) are the most common way in GIS to represent a form of uncertainty in decision problems. Fuzzy set membership functions are used to rescale variables as continuous factors in MCDA, whereas Boolean constraints correspond to crisp set membership functions.

The selected membership function should assign a correct relative priority for each pixel considering the suitability of the factor level for the objective pursued. The Decision Wizard module offers various options: linear, sigmoidal, J-shaped or user-defined functions.

The relationship between the factor and the suitability dictates the direction of the function: monotonically increasing when higher is the value factor, higher is the suitability level, monotonically decreasing when lower is the value factor, lower is the suitability level, and symmetric (increasing - plateau - decreasing).

Once selected the type and shape of the function, inflexion thresholds called control points must be set to adequate the curve to the specific factor being transformed. The factor value for those points does used to be empirical, similar to the values used in hard classification when converting a continuous map to classes. To be able to document any function, four control points are needed although in case of a monotonically relation, three controls points are the same:

a when suitability begins to be over 0 .

b when suitability is almost reaching its top (255).

c when suitability begins to be less than the maximum (255).

$\mathrm{d}$ when suitability is almost reaching its minimum (0).

\section{(d) Proposal for factors weighting}

Before initiating this process, it must be verified if a dependent relation exists between the factors in order to consider it when the relative weights will be fixed. To prove it, it is recommended at least to test linear regression between factors pairs. Weighting of factors depends on the influence of each factor in the studied problem and of its relative importance to determine the suitability for the considered objective.

To establish this importance and influence, it is advisable to ask for the support of group of experts, as well as target population representatives, and by consensus obtain the relative weight of each factor.

Weighting is realized by means of factor pairwise comparison following the Analytical Hierarchy Process (AHP) (Eastman 2012), which is automated in the Weight module and which consists in comparing each factor with all the other factors in a symmetric square matrix of dimension corresponding to the number of factors. The importance of the column factor comparing to the row factor is rated on a continuous scale of 9 levels with integer number 
when the row factor is more important than the column factor $(1,3,5,7,9)$ and at the opposite, the rate value is the reciprocal equivalent $(1 / 9,1 / 7,1 / 5,1 / 3)$. The diagonal has values of " 1 " since a factor comparing to itself has the same importance.

Moreover, the module calculates the consistency ratio (CR), which indicates the probability that the matrix scores were generated randomly. Matrix with $\mathrm{CR}>0.10$ should be corrected, modifying those scores until reaching a $\mathrm{CR} \leq 0.10$.

(e) Method for criteria evaluation or aggregation

This step is the actual MCAD as it combines the rescaled factor information and their relative weights (Saaty 1980). This aggregation can be realized in the Idrisi GIS through three logics: the Boolean intersection, the Weighted Linear Combination (WLC) and the Ordered Weighted Average. In this study case, the WLC method was selected because it gives a soft results comparing to the hard one by Boolean method, but also assume a medium risk for decision purpose (Eastman 2012). This method multiplies each factor map, which values have been previously adjusted to a common scale, with the relative weight assigned to the factor (each pixel of a same factor map is being applied the same factor weight), and finally sum the results (Chowdary et al. 2013).

(f) Identification of well with greater protection requirement

The final aggregation result of the MCDA is a raster that presents on a byte scale $(0-255)$ the suitability scores for protection priority $(\mathrm{Pp})$ against pollution inside the study zone.

To identify the wells with greater need of protection, the score value of the pixel where each well is located must be extracted from this final map, and those values are linked to the well database. Thus, based on the Pp linked to each well, the ranking of protection priority for the supply wells can be visualized as a map or as a table.

\section{Results and Discussion}

\subsection{Study Zone}

The method was tested in the Toluca Valley aquifer (TVA), which is located in the center region of the Mexican Republic. The aquifer covers a $2738 \mathrm{~km}^{2}$ surface and includes 27 municipalities, from which 23 have significant areas for analysis purpose.

The increase in population and economic activities has led to increased water requirements that are covered almost entirely with groundwater. Added to this fact, groundwater from this aquifer is exported to Mexico City and its metropolitan area, which means that this aquifer is undergoing an intensive exploitation with an extracting volume of $435.6 \mathrm{hm}^{3} /$ year, compared to a recharge of $336.8 \mathrm{hm}^{3} /$ year, which implies a deficit of $23 \%$ (CONAGUA 2009). $57 \%$ of the extracted water is used for urban public supply, $34 \%$ for industrial use and $9 \%$ for the remaining uses, primarily agricultural. The Mexico City supply is covered with a set of wells which extracts a total of $5.7 \mathrm{~m}^{3} / \mathrm{s}$ but has come to reach a $14 \mathrm{~m}^{3} / \mathrm{s}$ (Esteller and Diaz-Delgado 2002).

These extractions have resulted in a significant decrease of the groundwater table level, subsidence processes, springs and lakes drying, as well as decreased flows in rivers. To these negative results (Esteller and Diaz-Delgado 2002; Calderhead et al. 2011), it must be added the groundwater quality degradation, because of the increase in salinity as well as in heavy metal concentration (Fe and $\mathrm{Mn}$ ) and in nitrates (Esteller et al. 2012). The values of these parameters 
exceed the drinking limit set by Mexican law, with limit of $10 \mathrm{mg} / \mathrm{L}$ for $\mathrm{N}_{-} \mathrm{NO}_{3}$, and 0.30 and $0.15 \mathrm{mg} / \mathrm{L}$ for $\mathrm{Fe}$ and $\mathrm{Mn}$, respectively.

This zone presents two types of climate, one is humid temperate with rains in summer, which dominates in almost the whole surface, and the other is sub-humid semi-cold with summer rains which is observed in the Nevado de Toluca volcano (4600 masl) and its surroundings.

The Lerma River is the main surface flow, receiving wastewater from cities, as well as from the industrial parks. Chemical, paper and pulp, iron and steel, textiles, nonmetallic minerals, electroplating and tannery are the industries with greater risk according to its contamination level (CONAGUA-GTZ 2008).

Approximately, $81 \%$ of the population is concentrated in urban and suburban areas, the rest of the population is scattered in rural locations with conditions of marginalization, poverty and economic backwardness. The average sewer coverage is $73 \%$, including septic tanks or open channel and there are still some municipalities with a low coverage levels (CONAGUA-GTZ 2008).

\subsection{Indicators and Indices}

(a) Geodatabase

The basic information for the application of the proposed method is the following:

- Coordinates of the limiting polygon points defining the TVA (CONAGUA 2009).

- Raster image of the Digital Elevation Model (DEM), downloaded from the USGS (US Geological Survey) web site, given in meters above sea level units and UTM 14 NAD 27 reference system.

- Vector shapefile of the municipalities (INEGI 2007).

- Vector shapefile of GOD vulnerability index (Paredes 2007).

- Database of the INEGI (2007). This database includes data on geographic location, population structure, education level, indigenous language, housing and services.

- Mortality statistics by age group and death causes at municipality level (SSA 2007).

- Gross Domestic Product for year 2005 (IGECEM 2008).

- Vector shapefile of the land cover types from CONABIO (2001). The vector shapefile of industrial zones generated by Gómez (2005) was used.

- The database of the wells (CNA-IMTA 2003)

Although all the collected information covers the same geographic zone, the variables are using different unique identifier, which is why 7 geodatabases were structured and processed. These following geodatabases include the minimum required input information for the calculus of each indicator and index:

- Aquifer database: It contains the vector collection related to the aquifer polygon and the municipalities, and also the DEM.

- GOD database: It is constituted by the vector collection of the GOD vulnerability layer.

- PDI database: It consists of 2 vector collections, one for municipalities and one for localities with the entire corresponding census attributes. 
- HDI database: The identifier is the municipality code, using the municipality database to which life expectancy, education and gross domestic product indices were added.

- LU database: It integrates the vector collections of land cover types and industrial zones.

- Well database: the database includes 244 wells with the following information for each well: coordinates, registry number, and annual pumping rate (APR). Age well data (AGE) is missing that is why the registry year has been considered.

(b) Calculus of the indicators and indices

- GOD

The results of the GOD method are expressed within a range of four intervals, from "high" to "minimal" (Fig. 1a). The highest values of the index correspond to the most vulnerable area to pollution while the lowest values correspond to less vulnerable area. The area of high vulnerability can be finding in the aquifer recharge zones. The greatest part of the valley is of low vulnerability and the medium vulnerability zones occupy the smallest surface (Paredes 2007).

- PDI

The high values coincide with municipality and locality centers (Fig. 1b). The highest numbers correspond to urban populations of Toluca, Metepec, San Mateo Atenco, Zinacantepec; Xonacatlán; Tianguistenco and Ocoyoacac. Demographic density for the TVA in 2005 was of 7.5 inhab/ha a 14 times higher than the national average.

- HDI

Municipalities have values of HDI ranging from 0.53 to 0.76 and correspond to a medium human development. The lower values of HDI are related to Villa Victoria, Jiquipilco, Temoaya, Mexicaltzingo, Joquicingo and the highest values appear in Lerma, Toluca, Huixquilucan, Ocoyoacac y Metepec (Fig. 1c).

- LU

Eight categories of land use were ordered from lower to higher potential for groundwater pollution. The surface water bodies were classified as low polluting potential as there is no evidence of communication between them and the aquifer. Forest was also considered under the low polluting potential category. Pastures and rain fed agriculture were classified as medium polluting potential while land uses as industrial, urban and agricultural irrigation were assigned to the highest class (Fig. 1d).

- AGE

The records of the 244 studied wells presents a range of age values from 8 to 18 years, so none of the wells exceeded its useful life. 224 wells have less than 12 years, which means that $82 \%$ of the wells have not get yet half its useful life (Fig. 1e).

- $\quad$ APR

The supply sources that are extracting more water are located principally in Metepec, Tianguistenco, Zinacantepec, Lerma and Ocoyoacac. The range of pumping rate is large, with the lower value being $4563 \mathrm{~m}^{3} /$ year and the greater of $1892160 \mathrm{~m}^{3}$ / year (Fig. 1f). 

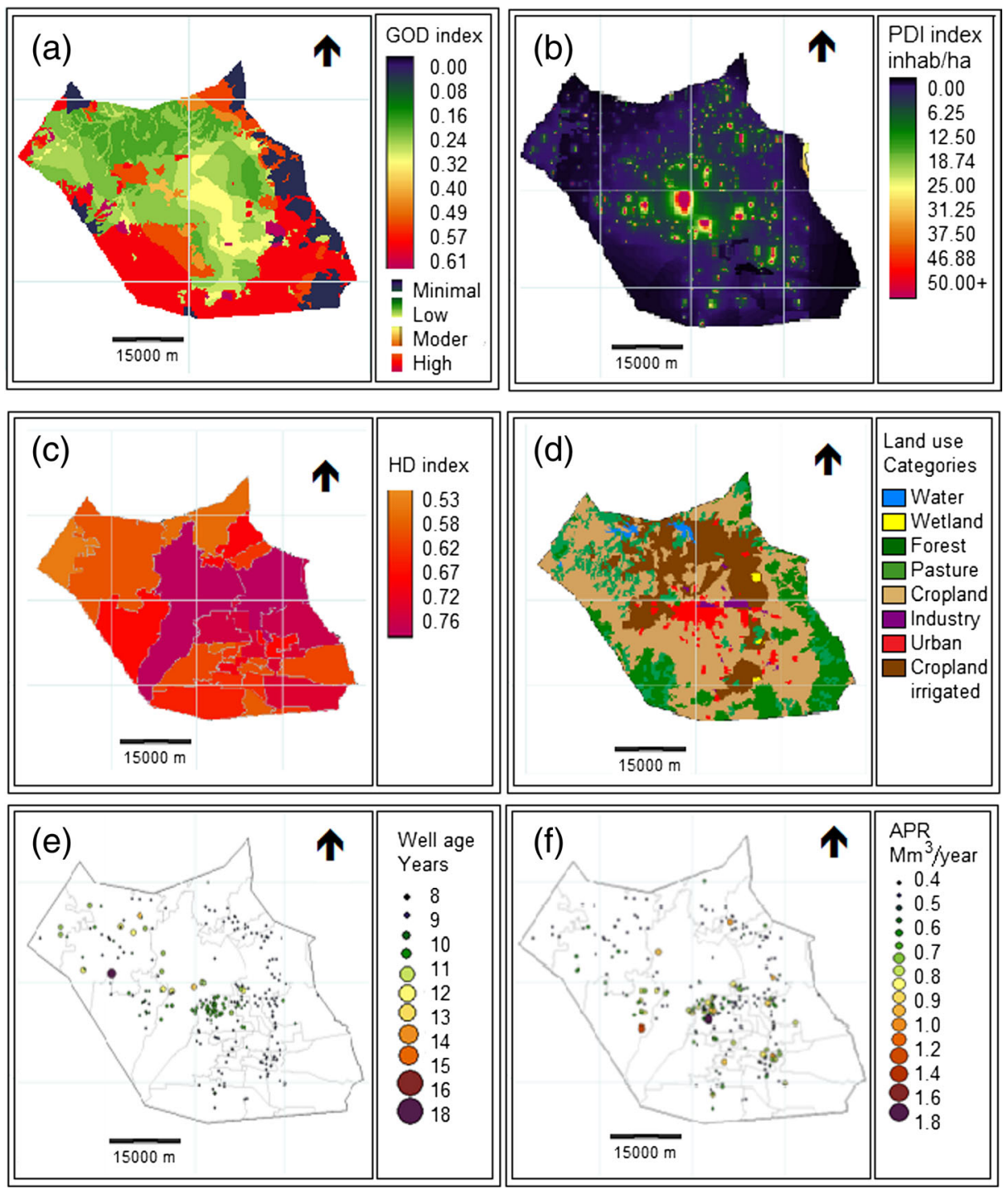

Fig. 1 Spatial distribution of the estimated values for the indicators and indices. a) GOD, b) Population indicator (PDI), c) Human development index (HDI), d) Land use (LU), e) Age well and (AGE), f) Annual pumping rates (APR)

\subsection{Geomatics Multi-Criteria Analysis}

The results of the fuzzy scaling factors with the Decision Wizard module were:

GOD: sigmoidal function, monotonically increasing. In the ideal case of having a raster with index values, so $a=0.1 \mathrm{y} b=0.7$, nevertheless each specific case must be revised since it does not always cover all the range of values of the GOD index. In this study case, where the whole range of GOD index values was not used, $a=0.1 \mathrm{y} b=0.5$, giving the greater priority to highly vulnerable zones. 
PDI: sigmoidal function, monotonically increasing. A density higher than 100 inhabitants/ha is considered of high polluting potential, while less than 50 is low according to the method POSH (Foster et al. 2002), and consequently a $=50$ and $b=100$. The greater protection priority was assigned to wells located in populated areas.

LU: sigmoidal function, monotonically increasing. All land use types are ordered from the less polluting to the higher potential, so $a=1$ y $b=$ identifier of the land use type most contaminating. Eight categories of land use were defined, thus $a=1$ y $b=8$.

HDI: sigmoidal function, monotonically decreasing. The study zone is considered as having a medium level of human development, establishing two subcategories, mid-low with HDI between 0.50 and 0.65 , and a mid-high with HDI between 0.65 and 0.80 . Municipalities with human development mid-low were considered as of first importance and as the calculated values are found between the same category and above all never reach the maximum limit, the $c=0.65$ and the $\mathrm{d}=0.75$.

AGE: sigmoidal function, monotonically increasing. The design useful life of water well has an average of 25 years. Thus, $a=1$ and $b=25$.

APR: sigmoidal function, monotonically increasing. The value for point "a" correspond to the consumed volume by one person in 1 year according to the domestic use per capita, and " $b$ " is assigned the value of the maximum extracted volume. The CNA (2000) indicates the consumption per capita, according to the regional annual mean temperature and the socioeconomic class. In the TVA, the water household consumption per capita was estimated to be around $180 \mathrm{~L} /$ person/day, and therefore, the annual amount spent by a person is $65.7 \mathrm{~m}^{3}$. Then, $\mathrm{a}=65.7 \mathrm{~m}^{3} /$ year and $\mathrm{b}$, which is the highest value for annual volume extracted, has a value of $892160 \mathrm{~m}^{3} /$ year.

The map results for raster rescaling of the factors are presented in Fig. 2.

\subsection{Criteria Weighting}

No significant dependent relation was found between the criteria when lineal regression was tested between them (the Pearson correlation values ranged between 0.1189 and -0.2920 ), consequently the criteria were considered as independent.

Criteria were weighted through the comparison of criteria pairs, for which an expert workshop took place, and thus conducted to obtain the relative weights (rw), with a CR of 0.1 so making acceptable the proposed weighting values.

The factor GOD is the one that most influence had in priority protection ranking $(\mathrm{rw}=0.5521)$. Socioeconomic criteria (PDI $\mathrm{rw}=0.0866$, HDI $\mathrm{rw}=0.0811)$, together result useful and obtain almost one third of the weight total. Meanwhile, the low score obtained by the index related to technical aspect (AGE rw $=0.0259$, APR $\mathrm{rw}=0.1096$ ), shows that well characteristics are having the lower influence for reaching the objective and from both, the lesser influent factor is the age of the supply source.

The criteria aggregation was done through the WLC. The software considered the obtained relative weight of factors in order to assign priority protection scores, thus 
A. Alvarado et al.
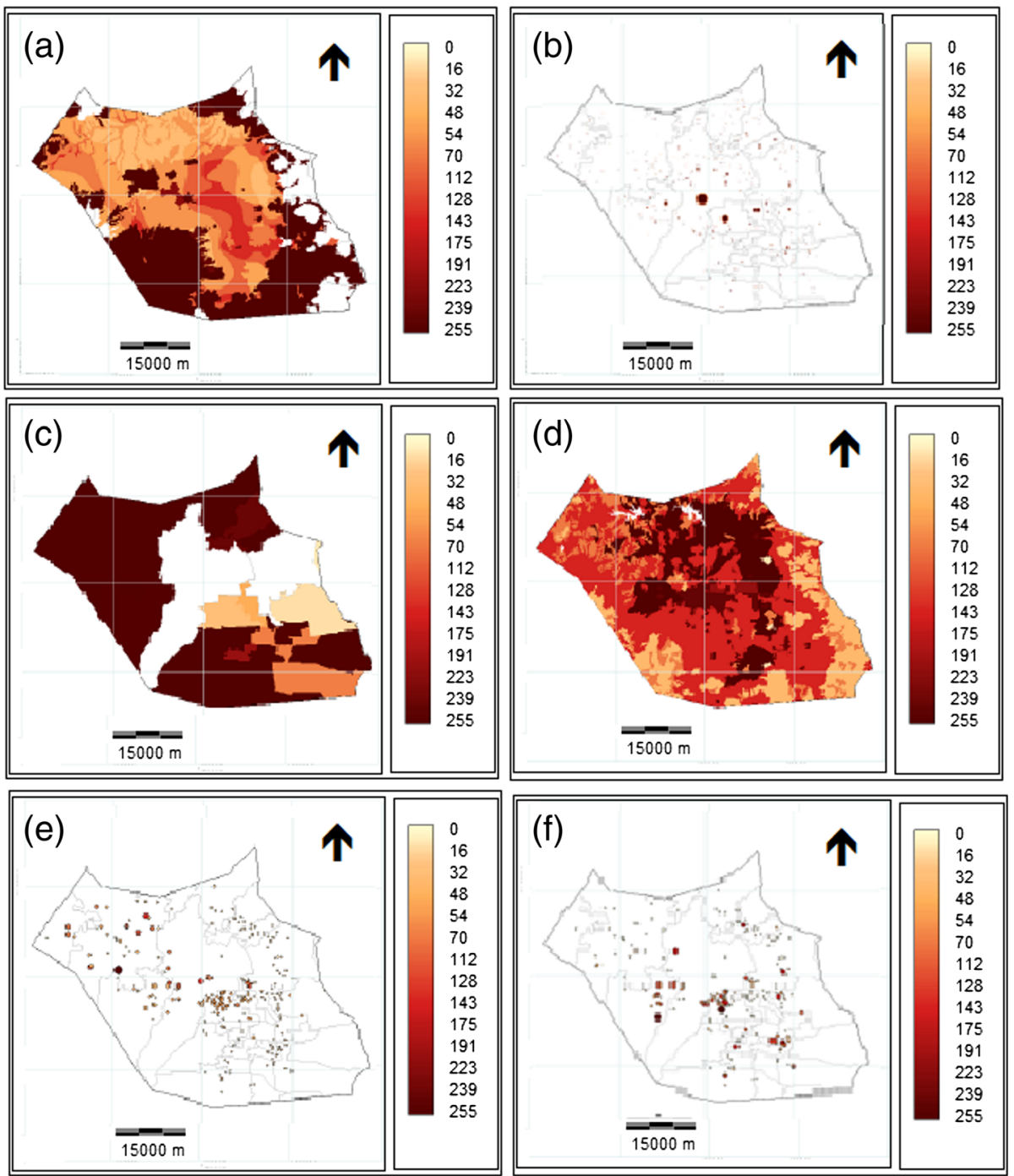

Fig. 2 Spatial distribution of the rescaling values for the factors. a) GOD, b) Population indicator (PDI), c) Human development index (HDI), d) Land use (LU), e) Age well (AGE), and f) Annual pumping rates (APR)

multiplying each pixel of the factor raster by its relative weight and afterwards added all the products, generating a resulting raster with the scores calculated as follows:

$$
\begin{aligned}
P p= & 0.0866 P D H+0.0811 H D I+0.1448 L U+0.5521 G O D+0.0259 A G E \\
& +0.1096 A P R
\end{aligned}
$$

where:

Pp Suitability score for protection priority. 
Fig. 3 a) Multi-criteria resulting map for the objective "protection priority"; b) Score map for TVA wells according to the protection priority
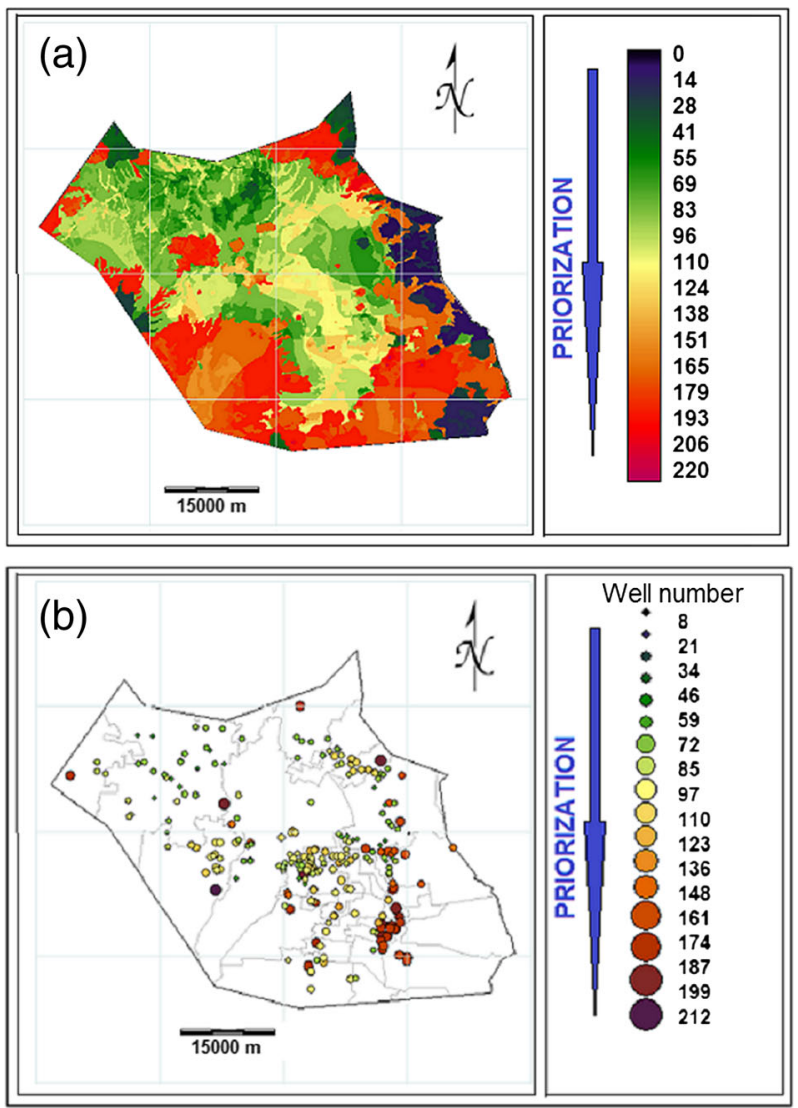

The protection priority map resulting from this process (Fig. 3a) show for each pixel the suitability value for protection priority, such as a higher score is equivalent to a more important protection priority, so with this type of map, it can be focused on the areas which need immediate protection.

The well identification with greater need for protection was completed by the extraction from the map in Fig. 3a of the score encountered where the well point figures, joining this data in a new field inside the table linked to the vector collection of the wells. This allows generating the vector map showing with proportional symbols the relative priority protection of the wells, as it can be visualized in Fig. $3 b$.

The Pp scores obtained for the 244 wells range from 0 to 204 with a mean of 116.23 and $25 \%$ of the wells are having score above 128 . The well with greater score (212) is located in

Table 2 Ranking of the well protection priority against pollution

\begin{tabular}{llll}
\hline Priority & Priority ranking & Number of wells & Percentage of wells (\%) \\
\hline 1 (high) & $144-212$ & 48 & 20 \\
2 (moderate) & $76-143$ & 180 & 74 \\
3 (low) & $\leq 75$ & 16 & 6 \\
\hline
\end{tabular}


Zinacantepec municipality and thus requires maximum priority, while the well with score of 8 in Lerma municipality is considered less critical. Based on the previous assumption, in order to simplify the ranking in protection priority of the wells, a reclassification in only 3 classes was done according to the ranges indicated in Table 2.

The main result gives in a database table, as well as in map visualization, the protection priority of each well, based on its score, and consequently, the wells with greatest need of being protected against pollution are clearly identified. With this information, groundwater administrators will be able to design well protection plans more efficient, moreover when economic and human resources for this purpose are scarce.

\section{Conclusions}

This development was based on the integration of socio-economic, environmental and technical criteria, represented by indicators and indices, which are calculated with information available for everyone. This type of calculus is less time-consuming than using a more complex groundwater modeling. By the way of MCDA, the priority of each groundwater supply source for public use was ranked in order to make them object of a protection program against pollution.

The key question in order to apply MCDA is, on one hand, the values that are given to the control point and, on another hand, the criteria weighting, which should be realized by an interdisciplinary panel (users, technical staff, non-governmental organisms, etc.).

Another key question is the choice of the logic to use for the criteria aggregation. In the actual case study, the WLC method was applied since it assumes an intermediate risk for decision taking.

The final map of suitable scores for protection priority allow to rank the priority protection of the different regions and the score map of well protection priority identifies in an clear and quick manner which wells need more protection measures. In the TVA it can be noted that the water supply wells needing protection are located mainly in the upper watershed, south-east of Toluca city, due to the characteristics of the aquifer.

Both maps are useful support for stakeholders in water governmental instances, since they let visualize where to assign technical, human and economic resources and initiate right actions for protecting the groundwater with an integrated vision of the issue. This prioritization process is relatively simple and not expensive.

Further research should include more parameters in the MCDA, for example water quality sampling results, whenever this information can be easily available.

Acknowledgments We thank anonymous reviewer for comments to improve the manuscript. This study was funded by Universidad Autónoma del Estado de México (Project 2600/2008U). Particular thanks are given to CONAGUA.

\section{References}

Adiat KAN, Nawawi MNM, Abdullah K (2012) Assessing the accuracy of GIS-Bases elementary multicriterio decision analysis as a spatial prediction tool-A case of predicting potential zone of sustainable groundwater resources. J Hydrol 440-441:75-89 
Calderhead AL, Therrien R, Rivera A, Martel R, Garfias J (2011) Simulating pumping-induced regional land subsidence with the use of InSAR and field data in Toluca Valley, Mexico. Adv Water Resour 34:83-97

Calizaya A, Meixner O, Bengtsson L, Berndtsson R (2010) Multi-criteria decision analysis (MCDA) for integrated water resources management (IWRM) in the Lake Poopo Basin, Bolivia. Water Resourc Manag 24:2267-2289

CESPEDES (Centro de Estudios del Sector Privado para el Desarrollo Sustentable) (2001) Índices de sustentabilidad ambiental: sustentabilidad ambiental comparada en las entidades federativas de México. CESPEDES, México

Chowdary VM, Chakraborthy D, Jeyaram A, Kirshana-Murthy YVN, Sharma JR, Dadhwal VK (2013) Multicriteria decision making approach for watershed prioritization using analytic hierarchy process technique and GIS. Water Resour Manage 27:3555-3571

CNA (Comisión Nacional del Agua) (2000) Manual de diseño de agua potable, alcantarillado y saneamiento. CNA, México

CNA-IMTA (Comisión Nacional del Agua -Instituto Mexicano de Tecnología del Agua) (2003) SIG Acuífero del Valle de Toluca. CNA-IMTA, México

CONABIO (Comisión Nacional para el Conocimiento y Uso de la Biodiversidad) (2001) Inventario Nacional Forestal. CONABIO, México

CONAGUA (Comisión Nacional del Agua) (2009) Actualización de la disponibilidad media anual de agua subterránea. Acuífero (1501) Valle de Toluca, Estado de México. CONAGUA, México

CONAGUA-GTZ (Comisión Nacional del Agua - Deutsche Gesellschaft für Technische Zusammenarbeit) (2008) Plan de Manejo de la Cuenca del Río Lerma en el Valle de Toluca. CONAGUA-GTZ, México

Custodio E, Llamas MR (1996) Hidrología Subterránea. Omega, Barcelona España

De Loë RC, Di Giantomasso SI, Kreutzwiser RD (2002) Local capacity for groundwater protection in Ontario. Environ Manag 29:217-233

Doumouya I, Dibi B, Kouame KI, Saley B, Jourda JP, Savane I, Biemi J (2012) Modelling of favourable zones for the establishment of water points by geographical information system (GIS) and multicriteria analysis (MCA) in the Aboisso area (South-east of Côte D'Ivore). Environ Earth Sci 67:1763-1780

Eastman JR (2012). IDRISI Selva Manual. Version 17.01. Clark Labs. Clark University.

Esteller MV, Diaz-Delgado C (2002) Environmental effects of aquifer overexploitation: a case study in the Highlands of Mexico. Environ Manag 29(2):266-278

Esteller MV, Rodríguez R, Cardona A, Padilla-Sanchez L (2012) Evaluation of hydrochemical changes due to intensive aquifer exploitation: study cases from Mexico. Environ Monit Assess 184:5725-5741

Exposito JL, Esteller MV, Paredes J, Rico C, Franco R (2010) Groundwater protection using vulnerability maps and wellhead protection area (WHPA). A case study in Mexico. Water Resour Manag 24:4219-4236

Foster S, Hirata R (1988) Groundwater pollution risk assessment: a methodology using available data. WHOPAHO/HPE-CEPIS Lima, Perú

Foster S, Hirata R, Gomes D, D'Elia M, Paris M (2002) Groundwater quality protection: a guide for water utilities in municipal authorities and environmental agencies. World Bank Publication Washington, USA

Gómez MA (2005). Desarrollo de una metodología geomática para la evaluación por subcuenca de indicadores de deficiencias en tratamiento de aguas residuales. Dissertation. Universidad Autónoma del Estado de México.

Hajkowicz S, Collins K (2007) A review of multiple criteria analysis for water resource planning and management. Water Resour Manag 21:1553-1566

IGECEM (Instituto de Información e Investigación Geográfica, Estadística y Catastral del Estado de México) (2008) Producto interno bruto municipal 2007. IGECEM, México

INEGI (Instituto Nacional de Estadística, Geografía e Informática) (2007). Base de datos de los Principales Resultados por Localidad, 2005 del II Conteo de Población y Vivienda INEGI. México

Joerin F, Cool G, Rodriguez MJ, Gignae M, Bouchard C (2010) Using multi-criteria decision analysis to assess the vulnerability of drinking water utilities. Environ Monit Assess 166:313-330

Karnib A (2004) An approach to elaborate priority preorders of water resources projects based on multi-criteria evaluation and fuzzy sets analysis. Water Resourc Manag 18:13-33

Korteling B, Dessai S, Kapelan Z (2013) Using information-gap decision theory for water resources planning under severe uncertainty. Water Resourc Manag 27:1149-1172

Kumar T, Gautam AM, Kumar T (2014) Appraising the accuracy of GIS-based multicriteria decision making technique for delineation of groundwater potential zones. Water Resourc Manag 28:4449-4446

López CLF, Rodríguez CL, Szekely M (2004) Medición del desarrollo humano en México. Estudios sobre desarrollo humano PNUD México.

Manzano R (2007). Diseño de base de geodatos demográficos e implementación geomática de indicadores e índices hídricos. Dissertation. Universidad Autónoma del Estado de México. 
Paredes J (2007) Análisis de la vulnerabilidad de acuíferos a la contaminación mediante la metodología GOD. Aplicación a los Acuíferos del Alto Lerma. Dissertation. Universidad Autónoma del Estado de México.

Ribas JR (2014) An assessment of conflicting intentions in the use of multipurpose water reservoirs. Water Resourc Manag 28:3989-4000

Saaty TL (1980) The analytical hierarchy process. McGraw-Hill, New York USA

SSA (Secretaría de Salud) (2007) Estadísticas de mortalidad 2005. SSA, México

UNPD (United Nations Development Programme) (2005) Human development record. UNPD, New York Zadeh LA (1965) Fuzzy sets. Inf Control 8:338-353 